\section{Medicina do Desejo: A Bioética diante dos desejos em Medicina}

Marchi, Neiva De

Psicológa, doutora em Bioética pelo C.U.S.C./SP, preceptora da residência médica na R.M.S, Sarandi/PR. Centro Universitário São Camilo. e-mail: neiva.marchi@hotmail.com

\section{Anjos, Márcio Fabri dos}

Professor, Coordenador do Programa de Doutorado em Bioética, C.U.S.C./SP; Secretário da SBB, membro da Câmara de Bioética do C.R.M./SP Centro Universitário São Camilo.

PALAVRAS-CHAVE: Autonomia pessoal, Bioética, Desejo, Medicina.

A Medicina contemporânea tem se deslocado dos objetivos curativos e preventivos da Medicina tradicional para uma Medicina que busca dar conta dos mais variados desejos. Baseada em sua natureza experimental e técnico-operatória, o avanço de determinadas práticas médicas favorecem um distanciamento de referências estáveis construídas pela coletividade. A justificativa para a disseminação dessas técnicas tem se pautado pela definição atual de saúde preconizada pela Organização Mundial da Saúde (1946), como um estado de bem-estar completo, físico, mental e social, e não apenas a ausência de doença. Assim, toda e qualquer técnica que vise melhorar a autoestima do indivíduo e provocar sua sensação de bem-estar é válida e justificável. A divulgação indiscriminada das possibilidades técnicas dessa Medicina tem sido utilizada como elemento de sedução, projetando ao conjunto da sociedade a ilusão de que podem realizar todos os desejos. Partindo do termo Medicina do Desejo de Gilbert Hottois e do estudo da Medicina que procura dar conta de desejos de Mathias Kettner, este estudo, norteado pela bioética hermenêutica crítica de Ricoeur, tem como objetivo compreender e discutir o desejo em demandas clínicas médicas sob uma perspectiva bioética. Os métodos da Bioética Latino-Americana levam rapidamente a suspeitas de que as demandas do desejo que ocorrem na medicina possam ser resultado de vários fatores interferentes na autonomia ou liberdade das pessoas. Estamos em tempos de profundas e radicais transformações em que as facilidades técnicas somadas ao crescimento da afirmação das autonomias subjetivas, colocam em pauta grandes questões éticas que emergem em diferentes áreas do agir humano. Verificamos o quanto o crescimento das autonomias paradoxalmente se torna uma ameaça para o próprio exercício delas, através de um grande jogo de disputa por defender os mais diversos interesses. Quando nos deparamos com a medicina motivada pelo desejo e suas consequências para a vida em sociedade, importa analisar mais profundamente o alcance que decisões privadas podem ter no corpo social.

\section{REFERÊNCIAS}

[1] GARRAFA, V. Bioética na América Latina: desafio ao poder hegemônico. Revista Bioética, Brasília, v. 22, n. 2, p. 213-224, 2014.

[2] HOTTOIS, Gilbert. Medicina do desejo. In: HOTTOIS, G.; MISSA, J-N. (Ed.). Nova Enciclopédia de Bioética. Lisboa: Instituto Piaget, 2001.

[3] KETTNER, Matthias (Org.). Wunscherfüllende Medizin. Ärztliche Behandlung im Dienst von Selbstverwirklichung und Lebensplanung. Frankfurt am Main: Campus, 2009. 338 p.

[4] _. The authority desire in medicine. In: DÜWELL, M.; REHMANN-SUTTER, C.; MIETH, D. The Contingent Nature of Life: Bioethics and Limits of Human Existence. Springer, 2008. p. 97-108.

[5] RICOEUR, Paul. Do texto à acçaõ - ensaios de hermenêutica II. Tradução de Alcino Cartaxo e Maria José Sarabando. Portugal: Rés Editora, 1989. 